\title{
THE ELECTRIC CURRENT FROM ESCHERICHIA COLI AND THE EFFECT OF RESIN ON IT ${ }^{1}$
}

\author{
HISAO MORISAKI \\ Institute for Agricultural Research, Tohoku University, Sendai \\ (Received October 1, 1981)
}

The mechanism of electric-current generation by Escherichia coli IAM 1016 and the effect of an anion-exchange resin on the amount of the current were investigated by using the electrode system developed by MAtSunaga et al. (1).

The current was increased by addition of succinic acid or glucose, and the increased current was diminished by arsenite. Rotenone and antimycin $A_{3}$, inhibitors of the respiratory chain, increased the current at lower concentrations and decreased it at higher. These results indicate that the current primarily results from respiratory activity, and that the source of electrons transferred to the electrode is located along the respiratory process.

The current was diminished by addition of the resin. This result suggests that electrons can be transferred from cells to resin as well as to the electrode.

The transfer of electrons to the resin changed the rate of glucose uptake and enhanced the respiratory activity of the organism.

Recently Matsunaga et al. (I) developed an electrode system for measuring microbial populations. They reported that Saccharomyces cerevisiae and Lactobacillus fermenti generated electric current when they came into contact with the electrode and that the amount of the current was proportional to the microbial population. But the mechanism of current generation was not fully understood.

On the other hand, the importance of the liquid-solid interface to microorganisms has been asserted by many authors. I supposed that the interface might affect the current, and that through this effect the physiological properties of microorganisms might be changed.

On this assumption I studied the following: (1) the mechanism of the current generation by E. coli; (2) the effect of an anion-exchange resin (Dowex 1) on the current; (3) the effect of the resin on the rates of glucose uptake and product formation.

1 Abbreviation used in this text is as follows: NB, the conventional nutrient broth. 


\section{MATERIALS AND METHODS}

Culture medium. Nutrient broth (NB) medium containing $10.0 \mathrm{~g}$ each of peptone (Kyokuto Co.) and meat extract (Kyokuto Co.), and $5.0 \mathrm{~g}$ of $\mathrm{NaCl}$ in $1,000 \mathrm{ml}$ of tap water was used. The $\mathrm{pH}$ value of this medium was adjusted to 7.0-7.2 using aqueous $\mathrm{NaOH}$.

Preparation of cell suspension. Cells of Escherichia coli IAM 1016 were preincubated at $30^{\circ}$ for $24 \mathrm{hr}$ in a test tube containing $10 \mathrm{ml}$ of NB medium. Twenty $\mathrm{ml}$ of pre-culture was inoculated into $200 \mathrm{ml}$ of NB medium in a $500 \mathrm{ml}$ Erlenmeyer flask. After incubation at $30^{\circ}$ for $19-20 \mathrm{hr}$ with stirring, the contents were centrifuged for $10 \mathrm{~min}$ at $8,000 \times g$ and $4^{\circ}$. The supernatant liquid was decanted and the precipitated cells were washed several times with phosphate buffer solution $(0.1 \mathrm{M}, \mathrm{pH} 7.0)$. The cells were then resuspended in $100 \mathrm{ml}$ of the phosphate buffer solution. The population of the cell suspension was determined using a haemacytometer.

Apparatus and measurement of electric current. The electrode system developed by Matsunaga et al. (1) was used. The system consisted of two electrodes: one was covered with cellulose dialysis membrane (catalog no C-65, Sanko Pure Pharmaceutical Co.) at the anode (reference electrode) and the other was not (determination electrode). Each electrode used in this study consisted of a platinum anode ( $2 \mathrm{~cm}$ diameter), silver peroxide cathode $\left(\mathrm{Ag}_{2} \mathrm{O}_{2}, 1\right.$ by $\left.4 \mathrm{~cm}\right)$, and anionexchange membrane (Selemion type AMV, Asahi Glass Co.) as a separator. Catholyte was the phosphate buffer solution.

The cell suspension $\left(2-3 \times 10^{9} \mathrm{cells} / \mathrm{ml}\right)$ was kept at $30^{\circ}$, with stirring by magnetic stirrer. Steady-state current was observed about 15 min after the immersion of the electrodes.

Correction of electric current. Cells or other materials may be adsorbed onto the platinum anode or onto the cellulose dialysis membrane; this adsorption may cause a change in the efficiency of electron transfer. To correct the change, the sensitivity of each electrode was determined before and after each experiment. To estimate the sensitivity, electric current generated by addition of $100 \mu 1$ of methanol to $100 \mathrm{ml}$ of the phosphate buffer was adopted: methanol is an electroactive substance with molecule small enough to penetrate through the cellulose membrane. The measured current, obtained from the cell suspension, was divided by the sensitivity and corrected current was gained: assume two electrodes A and $\mathrm{B}$, the sensitivity of $\mathrm{A}$ being twice as large as that of $\mathrm{B}$; the measured current of A will be twice as large as that of $B$, so quotients (the measued current/the sensitivity) of each electrode will give corrected currents. The current generated by the organism was obtained as the difference between the corrected currents of the two electrodes: the current of the reference electrode was due to electroactive substances which can penetrate through the cellulose membrane; the current of the determination electrode was due to the electroactive substances and transfer of electrons from cell to electrode; thus the electrode system is appropriate for 
measuring direct transfer of electrons from cell. By the correction, each current was normalized and better results were obtained.

Resin. Anion-exchange resin (Dowex 1-X4, C1 form, 200-400 mesh) was used.

Inhibitors. Aqueous sodium arsenite (125 mm, Kanto Chemical Co.) was used as inhibitor for pyruvic dehydrogenase. Rotenone (Nakarai Chemical Ltd.) and antimycin $\mathrm{A}_{3}$ (Sigma Chemical Co.) dissolved in ethanol (rotenone; $2.8 \times$ $10^{-4} \mathrm{M}$, antimycin $\mathrm{A}_{3} ; 4.8 \times 10^{-4} \mathrm{M}$ ) were used as inhibitors of the respiratory electron-transport chain.

Measurement of glucose concentration. Five hundred $\mathrm{mg}$ of glucose was added to $100 \mathrm{ml}$ of cell suspension $(28 \mathrm{~mm})$, and the suspension was kept at $30^{\circ}$ with stirring. Five $\mathrm{ml}$ of the suspension was pipetted out at one hour intervals after $1 \mathrm{hr}$ of incubation. These samples were immediately cooled in a refrigerator, and further consumption of glucose was stopped. In the experiment using the resin, the resin was added after $4 \mathrm{hr}$ incubation with glucose. Samples were centrifuged at $8,000 \times g$ and $4^{\circ}$ for $10 \mathrm{~min}$. Supernatants were used to determine glucose concentration by use of the phenol-sulfuric acid reaction (2).

Rate of glucose uptake. Glucose was consumed by a first-order reaction, so the natural logarithm of glucose concentration was plotted against time. The rate of glucose uptake was calculated from the slope of the regression line gained by a least squares fit of the plots, and the estimated standard error of the slope was also calculated (3).

Analysis of product. Except for $\mathrm{CO}_{2}$, all products were analyzed by gas chromatography (Yanagimoto G8). As a packing reagent, diethylene glycol succinate (Wako Pure Chem. Ind. Ltd.) for methyl lactate and succinate, FAL-M (Wako Pure Chem. Ind. Ltd.) for acetic acid, and TENAX-GC (Nihon Chromato Ind. Co.) for ethanol were used. The concentrations of each product were not reduced by addition of the resin, but were increased by first order reaction. Thus the adsorption of each product to the resin seems to be negligibly small. The rate of $\mathrm{CO}_{2}$ formation was estimated by collecting ${ }^{14} \mathrm{CO}_{2}$ produced during consumption of ${ }^{14} \mathrm{C}$-labelled glucose. Seven $\mu \mathrm{Ci}$ of $\left[{ }^{14} \mathrm{C}(\mathrm{U})\right]$-glucose $(2.2 \mathrm{mCi} / \mathrm{mmol}$, New

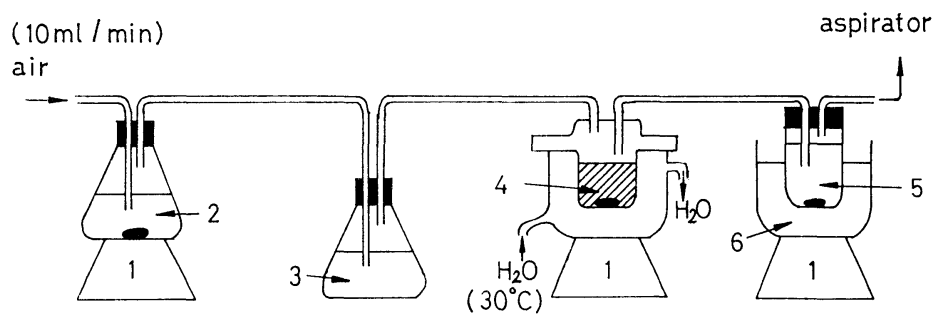

Fig. 1. Experimental equipment for trapping carbon dioxide.

1, Magnetic stirrer; 2, aqueous sodium hydroxide $(2 \mathrm{~N}) ; 3$, distilled water; 4, cell suspension of $E$. coli; 5 , Carbo-sorb II, cocktail for trapping carbon dioxide; 6 , ice bath. 
England Nuclear) was added to the cell suspension with $500 \mathrm{mg}$ of glucose, and at one hour intervals $1 \mathrm{ml}$ portions of Carbosorb II, carbon dioxide absorber (Packard Inst. Co.), were pipetted out. Samples were then added to $10 \mathrm{ml}$ of Permafluor V, a scintillation cocktail (Packard Inst. Co.). The radioactive intensity of the trapped ${ }^{14} \mathrm{CO}_{2}$ was measured by liquid scintillation counter (Kobe Kogyo Co., GSL-263). Figure 1 shows the experimental equipment for trapping ${ }^{14} \mathrm{CO}_{2}$.

\section{RESULTS}

Electric current generated by E. coli

The current difference between determination and reference electrodes was proportional to cell population (Fig. 2): the proportional relation was observed in other twice-performed experiments.

These results coincide with the observation of Matsunaga et al. (1). Here-

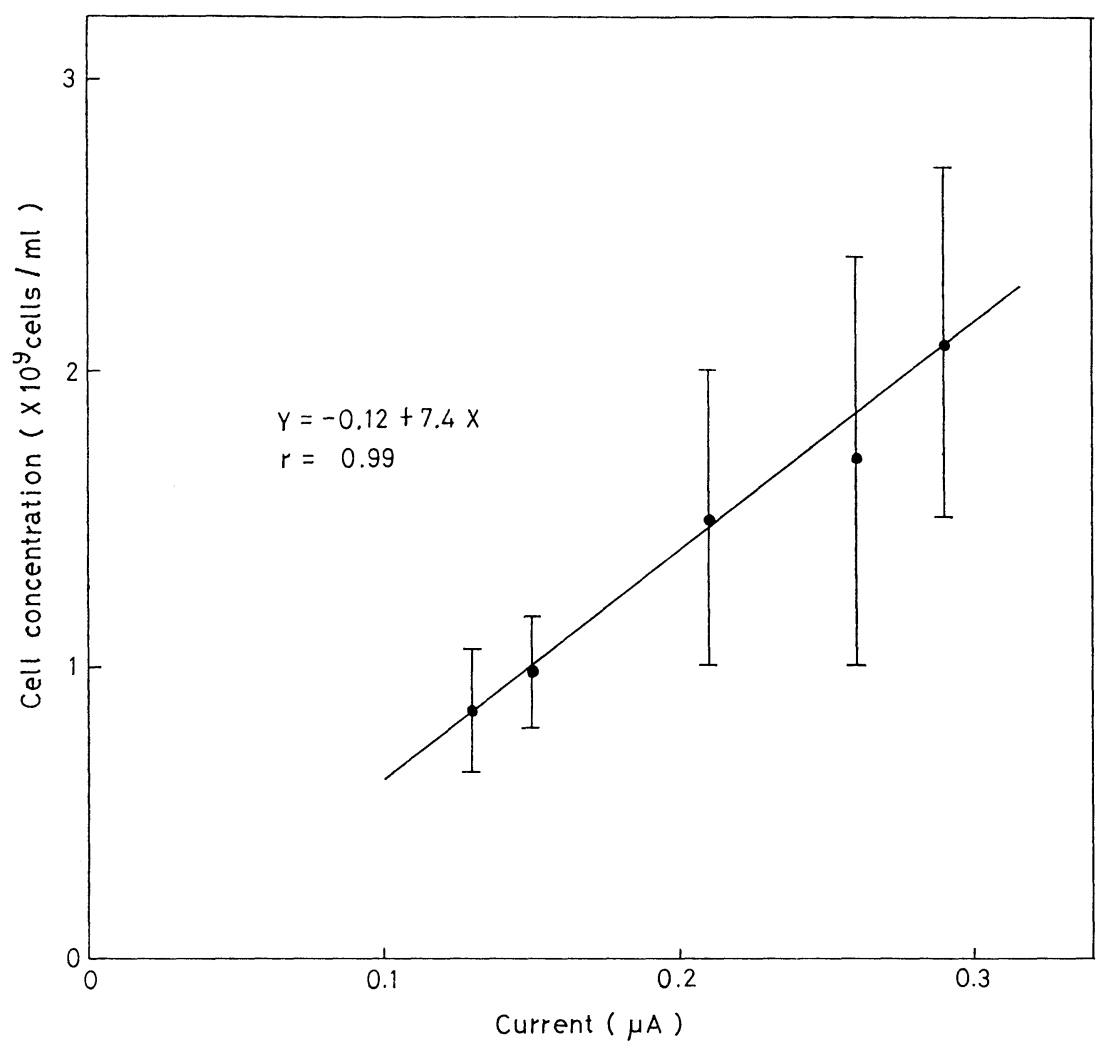

Fig. 2. Relation between cell concentration and electric current from E. coli.

Abscissa indicates electric current (uncorrected) from E. coli. $\Phi$, mean and range of 2 measurements. 
after the current difference will be described only as the current, unless especially cited otherwise.

\section{Effect of substrate}

The current from the cell is expected to be increased when the activity of the organism is enhanced by addition of substrate. Succinic acid and glucose increased the current, as expected, as their concentrations increased (Fig. 3a, Fig. $3 b)$.

The correlations of the Michaelis-Menten type were obtained in both cases, and a remarkable increase in the current was observed in the case of glucose (Fig. 3b).

These results clearly show that the current closely correlates with the metabolic activity of the organism.

\section{Effect of arsenite}

Figure $4 \mathrm{a}$ shows that the current increased by succinic acid was diminished by arsenite, which inhibits dehydrogenase containing dithiols, e.g. pyruvic dehydrogenase. Similar result was obtained in the case of glucose (Fig. 4b).

With arsenite, the rate of glucose uptake was hardly affected, however, that of succinic acid was diminished. The decrease in the rate of succinic acid uptake is interpreted by the fact that arsenite inhibits TCA-cycle activity. Little change in the rate of glucose uptake suggests that the fermentative process, by which

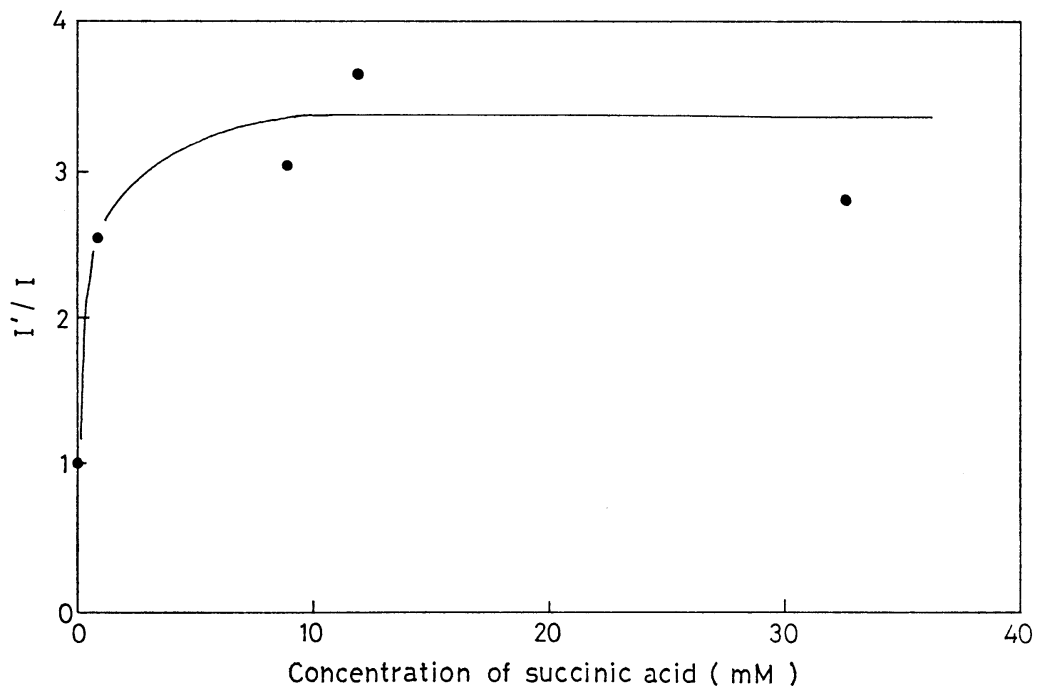

Fig. 3a. Relation between concentration of succinic acid and electric current from E. coli.

$I$, the current before adding succinic acid; $I^{\prime}$, the current after adding succinic acid. 


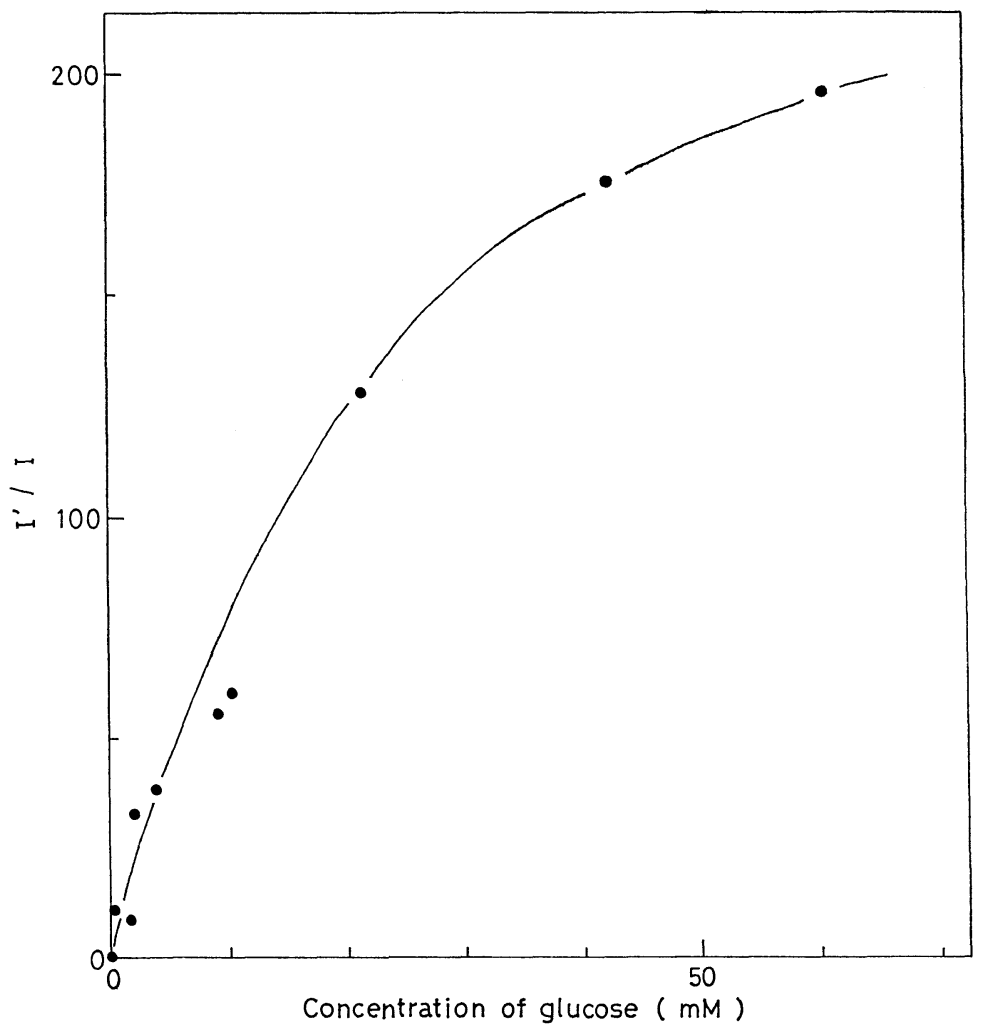

Fig. 3b. Relation between glucose concentration and electric current from E. coli. $I$, the current before adding glucose; $I^{\prime}$, the current after adding glucose.

glucose was mostly consumed (ca. $96 \%$ ) as shown later in Fig. 7, was not affected by arsenite.

We may consider that the decrease in the current shown in Figs. 4a and $4 \mathrm{~b}$ is ascribed to the decrease in respiratory activity and, consequently, that the current results mainly from the respiratory activity.

\section{Effect of inhibitor of respiratory chain}

To elucidate the source of electrons transferred from cell to electrode, the effect on the current of the inhibitors rotenone and antimycin $\mathrm{A}_{3}$ specific for respiratory electron transport was investigated (Table 1).

The ratio $\left(I^{\prime} / I\right)$ of the current after addition $\left(I^{\prime}\right)$ to that before addition $(I)$ of an inhibitor increased with inhibitor concentration, although the ratio decreased at higher concentrations in both cases.

The increase in the ratio at lower concentrations may reflect the enhancement of the electron transfer from cell to electrode: more electrons may be accumulated 


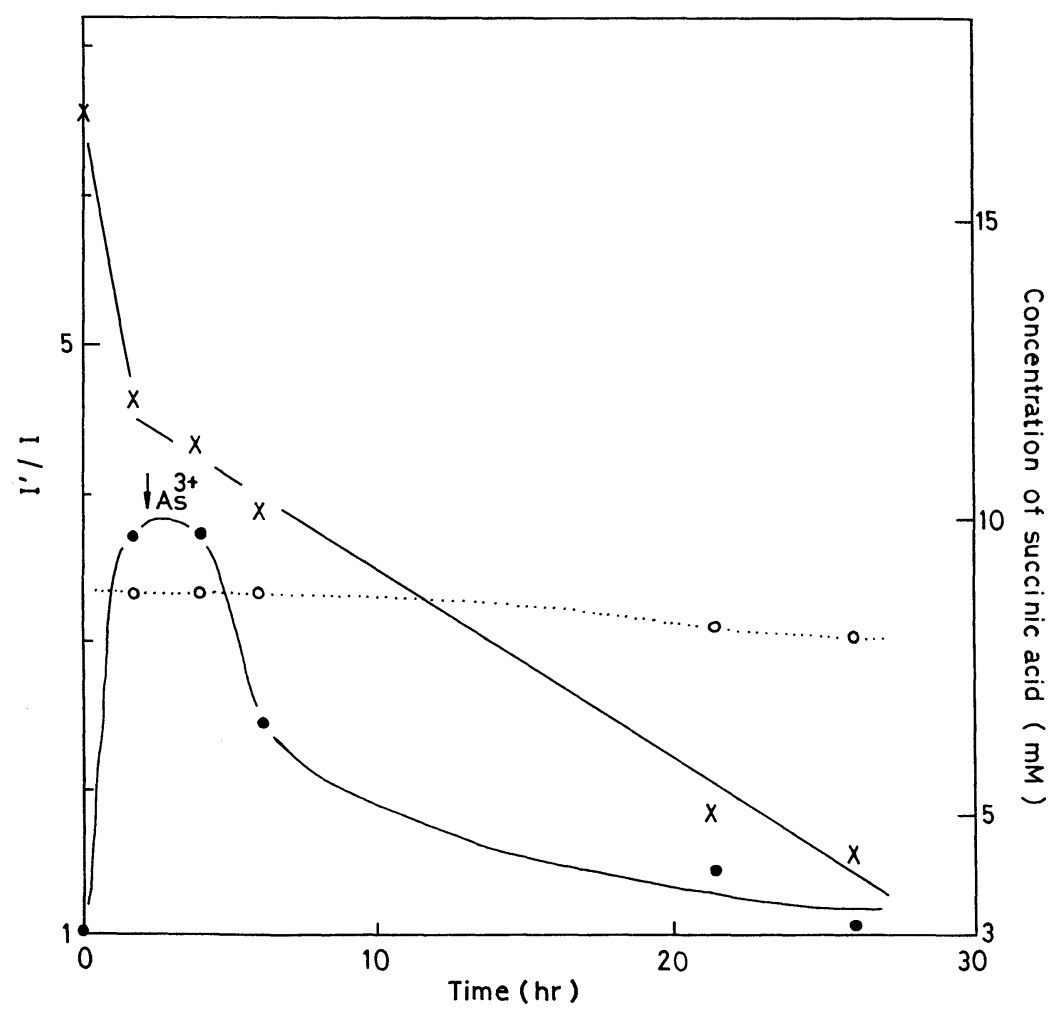

Fig. 4a. Effect of arsenite on the current from E. coli metabolizing succinic acid. Succinic acid was added at $0 \mathrm{hr}(16.8 \mathrm{~mm})$, and arsenite at $2.4 \mathrm{hr}(2.55 \mathrm{~mm}) . \quad I$, the current before adding succinic acid; $I^{\prime}$, the current after adding succinic acid; $\bullet$, measured value $\left(I^{\prime} / I\right)$; $\bigcirc$, expected value $\left(I^{\prime} / I\right)$ from the relation in Fig. $3 \mathrm{a} ; \times$, concentration of succinic acid.

at the source of electrons through the interruption of electron flow by these inhibitors. As the concentration of such inhibitors increases, other functioning as well as that of the respiratory chain may be diminished, which may result in the decrease in the current.

From these results we may assume that the source of electrons is located along the respiratory process.

\section{Effect of resin}

Ion-exchange resin has been used to investigate the effect of interface on microorganisms by several authors (HATTORI et al., 4,5; HATtoRI, 6). I investigated whether there is any effect of anion-exchange resin on the current (Fig. 5a, Fig. 5b).

In both cases with and without addition of glucose, the current diminished 


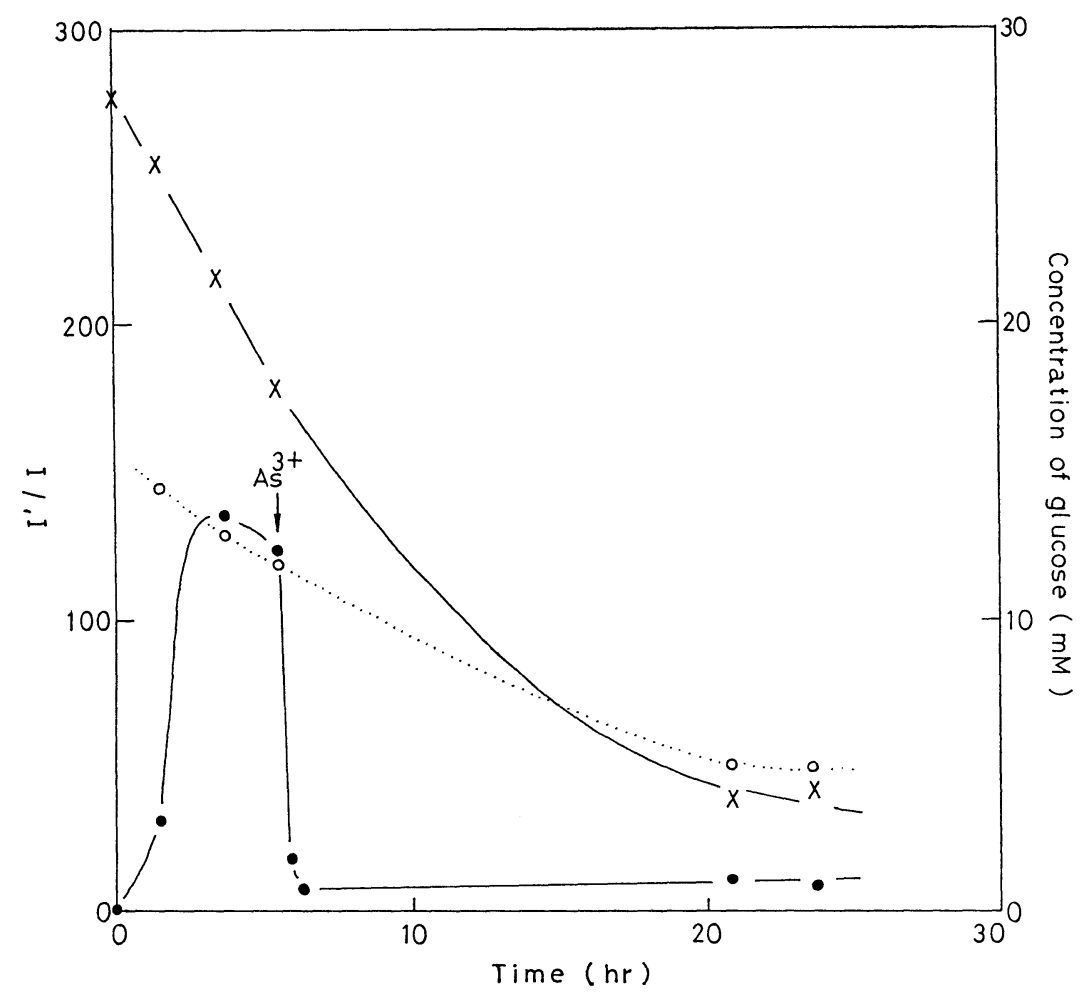

Fig. 4b. Effect of arsenite on the current from E. coli metabolizing glucose.

Glucose was added at $0 \mathrm{hr}(28.2 \mathrm{mM})$, and arsenite at $5.5 \mathrm{hr}(2.66 \mathrm{~mm})$. I, the current before adding glucose; $I^{\prime}$, the current after adding glucose; $\bullet$, measured value $\left(I^{\prime} / I\right) ; \bigcirc$, expected value $\left(I^{\prime} / I\right)$ from the relation in Fig. $3 b ; \times$, concentration of glucose.

corresponding to the amount of resin added, and reached a minimum at amounts larger than about $3 \mathrm{mg} / 10^{9}$ cells.

Since the change, caused by adsorption of the cells to the resin, in the number of cells freely suspended in the bulk solution was too small to detect, the decrease in the current was not due to the decrease in the number of free cells. Therefore the decrease in the current caused by addition of the resin can be ascribed to the decrease in electron transfer from free cells to electrode, in the way of competition between the resin and the electrode.

\section{Effect of resin on rate of glucose uptake}

The time course of glucose uptake obeyed the kinetics of a first order reaction. This was true in the presence of the resin. The regression lines defined for the plots of natural logarithms of glucose concentrations against time by least squares fit showed good linearities: correlative coefficients were 0.998 and 0.999 in double experiments without the resin. From the slope of a regression line, the rate of 
Table 1. Effect of inhibitors on electric current from E. coli.

\begin{tabular}{|c|c|c|c|c|}
\hline \multirow{2}{*}{ Inhibitor } & \multirow{2}{*}{$\begin{array}{c}\text { Concentration } \\
\text { of inhibitor } \\
(\mu \mathrm{M})\end{array}$} & \multicolumn{3}{|c|}{ Current $(\mu \mathrm{A})$} \\
\hline & & $\begin{array}{c}\text { before addition } \\
I\end{array}$ & $\underset{I^{\prime}}{\operatorname{after}}$ & $I^{\prime} / I^{a}$ \\
\hline \multirow[t]{10}{*}{ Rotenone } & 0.071 & 1.36 & 3.07 & 2.26 \\
\hline & 0.086 & 0.62 & 1.26 & 2.03 \\
\hline & 0.14 & 0.60 & 1.44 & 2.40 \\
\hline & 0.14 & 0.45 & 1.15 & 2.56 \\
\hline & 0.19 & 1.00 & 2.77 & 2.77 \\
\hline & 0.23 & 0.55 & 2.19 & 3.98 \\
\hline & 0.41 & 1.00 & 3.96 & 3.96 \\
\hline & 0.57 & 0.77 & 2.38 & 3.09 \\
\hline & 0.69 & 0.66 & 1.67 & 2.53 \\
\hline & 1.4 & 1.66 & 2.93 & 1.77 \\
\hline \multirow[t]{9}{*}{ Antimycin $\mathrm{A}_{3}$} & 0.49 & 1.40 & 2.61 & 1.86 \\
\hline & 1.1 & 1.13 & 2.59 & 2.29 \\
\hline & 1.5 & 1.00 & 1.55 & 1.55 \\
\hline & 2.2 & 1.40 & 2.26 & 1.61 \\
\hline & 2.7 & 0.90 & 1.71 & 1.90 \\
\hline & 3.1 & 0.90 & 2.75 & 3.06 \\
\hline & 4.9 & 0.96 & 3.63 & 3.78 \\
\hline & 6.4 & 1.66 & 4.74 & 2.86 \\
\hline & 7.3 & 2.52 & 6.70 & 2.66 \\
\hline
\end{tabular}

a The ratio of the current after addition to that before addition of an inhibitor. For each inhibitor concentration a different cell-suspension was used.

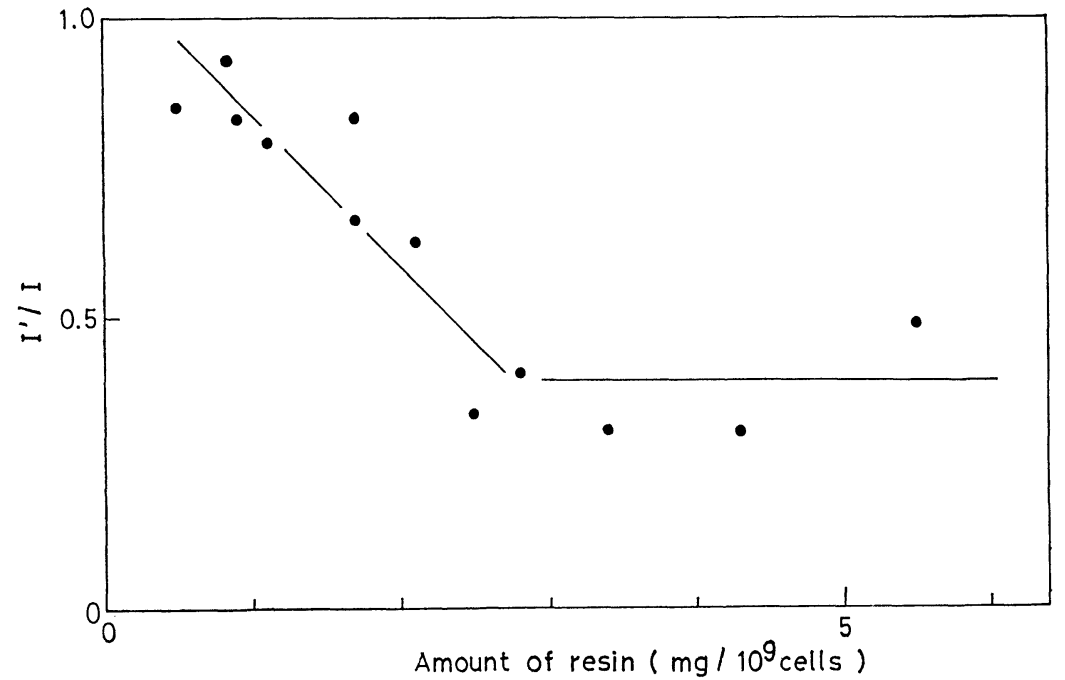

Fig. 5a. Effect of resin on the current from E. coli.

$I$, the current before adding the resin; $I^{\prime}$, the current after adding the resin. 


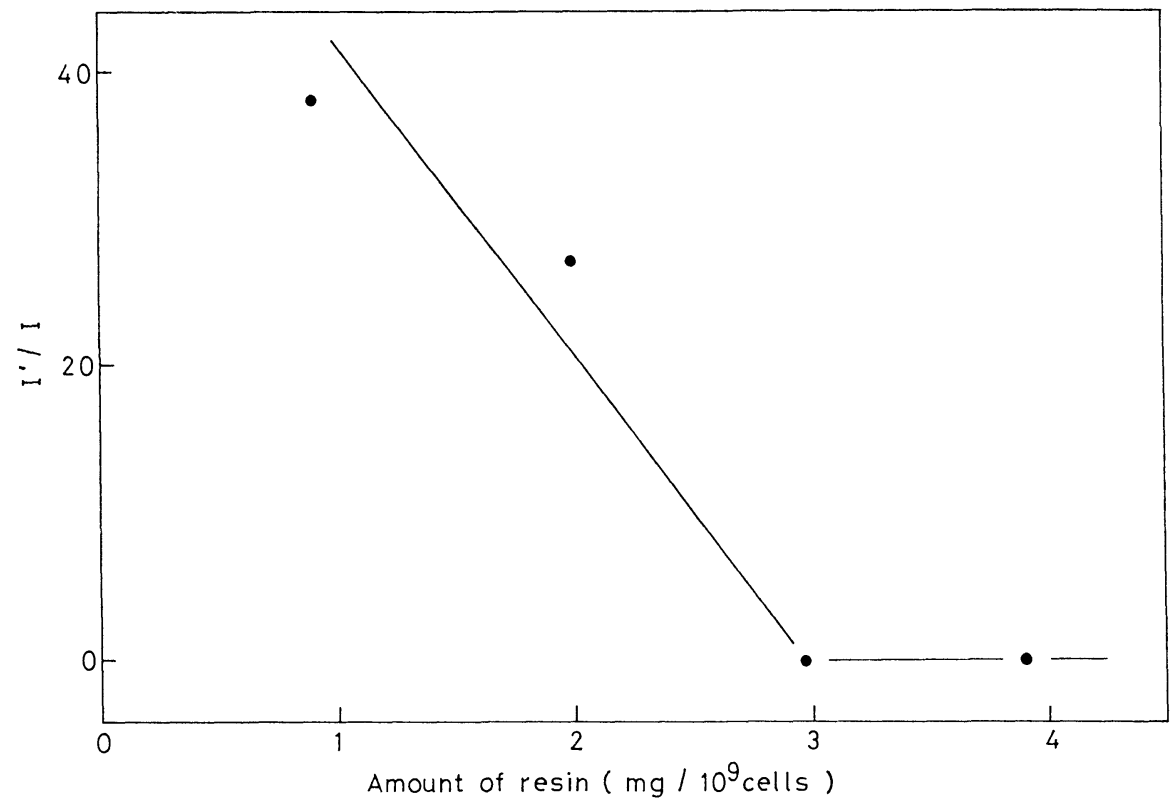

Fig. 5b. Effect of resin on the current from E. coli metabolizing glucose.

Glucose concentration was about $28 \mathrm{~mm}$. I, the current before adding glucose and the resin; $I^{\prime}$, the current after adding glucose and the resin.

glucose uptake was estimated.

The rate increased according to the amount of the resin added up to 3-4 mg/ $10^{9}$ cells; an example is shown in Fig. 6. When a larger amount of the resin was added, the rate decreased a little (Table 2).

Table 2 shows that a relation enhancing glucose uptake exists between cell and the resin. With larger amounts of resin, this relation may be offset by another reducing glucose uptake.

Effect of resin on product

Assuming a product (f) formed by a first order reaction at a rate constant of $k_{\mathrm{f}}$ :

$$
\text { glucose } \underset{k_{\mathrm{r}}}{\longrightarrow} \mathrm{f}
$$

we have

$$
\mathrm{d}[\mathrm{f}] / \mathrm{d} t=k_{\mathrm{f}}[\text { glucose }]=k_{\mathrm{f}}[\text { glucose }]_{\mathrm{O}} e^{-k t} .
$$

Integration of equation (1) gives

$$
[\mathrm{f}] /[\text { glucose }]_{\mathrm{O}}=[\mathrm{f}]_{\mathrm{o}} /[\text { glucose }]_{\mathrm{O}}+\left(k_{\mathrm{f}} / k\right)\left(1-e^{-k t}\right)
$$

where [f] and [f] $]_{0}$ are the concentrations of product (f) at time $t$ and 0 respectively, [glucose] and [glucose] $]_{0}$ are the concentrations of glucose at time $t$ and 0 respective- 


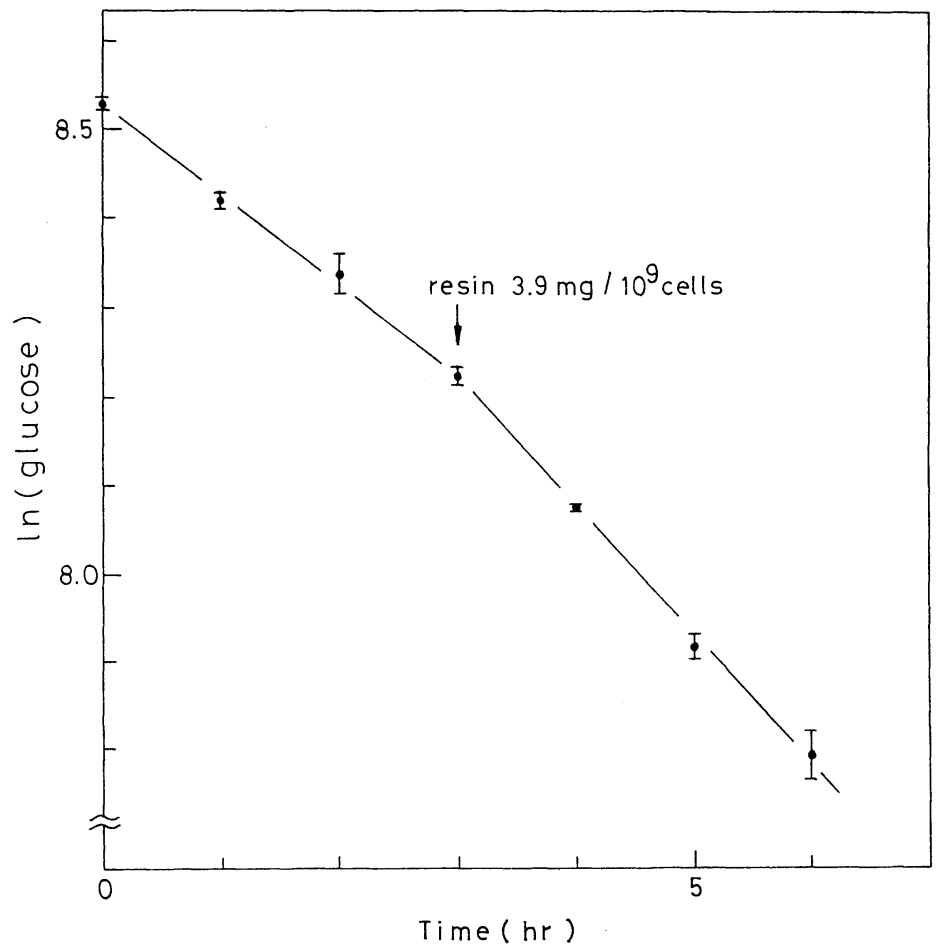

Fig. 6. Effect of resin on the rate of glucose uptake. Ordinate indicates natural logarithm of millimolar concentration of glucose. $\Phi$, mean and range of 2 measurements.

Table 2. Effect of resin on rate constant of glucose uptake.

\begin{tabular}{cccc}
\hline \multirow{2}{*}{$\begin{array}{c}\text { Amount of resin } \\
\left(\mathrm{mg} / 10^{9} \text { cells }\right)\end{array}$} & \multicolumn{2}{c}{ Rate constant $\left(\times 10^{-4} \mathrm{~min}^{-1}\right)$} & $k / k_{\mathrm{O}}$ \\
\cline { 2 - 4 } & \multicolumn{1}{c}{$k_{\mathrm{O}}{ }^{a}$} & \multicolumn{1}{c}{$k^{b}$} & 1.12 \\
0.73 & $12.1(0.43)^{c}$ & $13.5(1.2)^{c}$ & 0.92 \\
1.0 & $14.8(0.77)$ & $13.6(0.46)$ & 1.42 \\
1.4 & $14.9(2.3)$ & $21.1(0.63)$ & 1.36 \\
1.9 & $15.8(1.1)$ & $21.5(1.1)$ & 1.37 \\
2.2 & $8.23(0.62)$ & $11.3(1.3)$ & 1.35 \\
2.4 & $13.8(2.1)$ & $18.6(1.3)$ & 1.37 \\
3.2 & $8.05(0.92)$ & $11.0(1.8)$ & 1.46 \\
3.9 & $16.6(0.72)$ & $24.2(0.79)$ & 1.11 \\
4.0 & $11.5(1.2)$ & $12.8(0.77)$ & 1.09 \\
4.3 & $10.4(0.18)$ & $11.3(0.74)$ & 1.02 \\
5.0 & $14.2(0.47)$ & $14.5(1.2)$ & 0.82 \\
5.1 & $12.3(1.3)$ & $12.7(0.45)$ & 0.77 \\
6.4 & $7.79(0.03)$ & $6.40(0.75)$ &
\end{tabular}

$a$ The rate constant before adding the resin.

$b$ The rate constant after adding the resin.

$c$ The estimated standard error. 


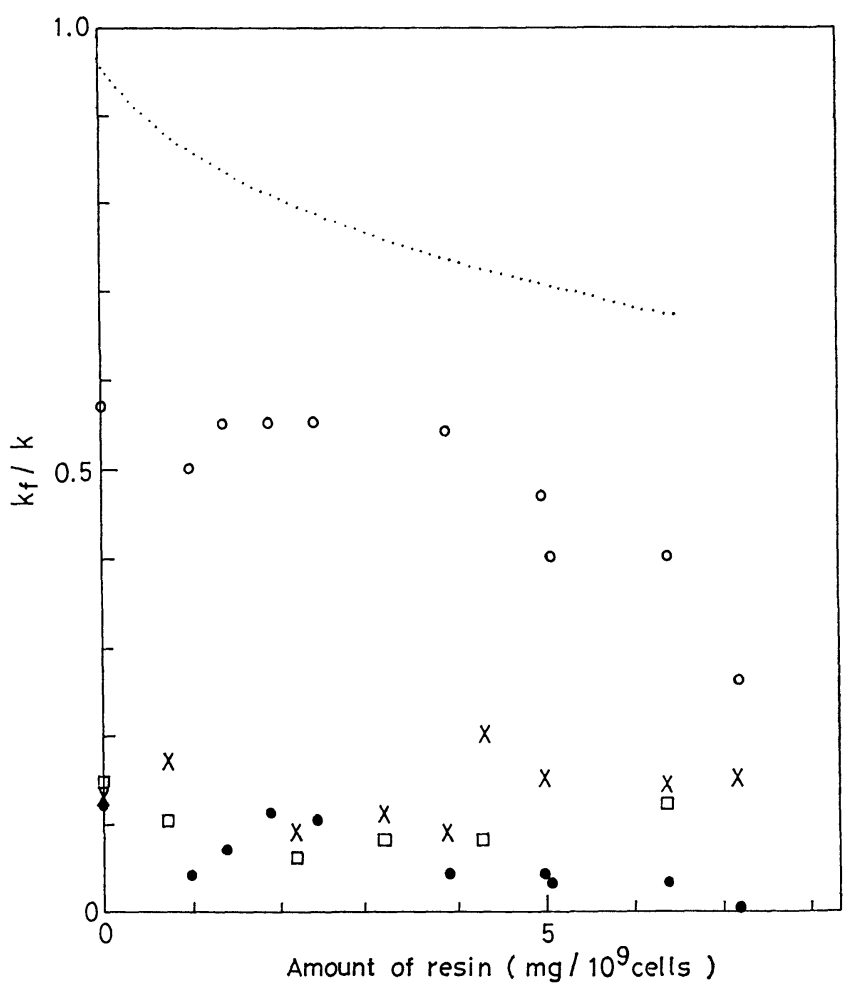

Fig. 7. Effect of resin on the rates of product formations.

$k$, rate constant of glucose uptake after adding the resin; $k_{\mathrm{f}}$, rate onstant of each product formation after adding the resin, corrected by the number of carbons. Dotted line shows the summation of the ratio of each product formation. Ethanol was evaporated by a first order reaction at the rate constant of $2.5 \times 10^{-3} \mathrm{~min}^{-1}$; by this constant the rate constant of ethanol formation was corrected. $\bigcirc$, lactic acid; $\bullet$, succinic acid; $\times$, acetic acid; $\square$, ethanol.

ly, $k$ is the rate constant of glucose uptake, and $t$ is time. [f]/[glucose $]_{0}$ was plotted against $\left(1-e^{-k t}\right)$, and the ratio $k_{\mathrm{f}} / k$, the rate constant of product (f) formation to the rate constant of glucose uptake, was obtained from the slope of the regression line by a least squares fit of the plots.

Lactic acid, succinic acid, acetic acid, and ethanol were detected as the fermentative products. Good linearities were obtained in the regression lines: correlative coefficients were larger than 0.99 . This result suggests that each product was really produced by the first order reaction.

The effect of the resin on the ratio $k_{\mathrm{f}} / k$ of each product formation is shown in Fig. 7.

The ratios of lactic and succinic acid formation were decreased as the amount of the resin increased, while the changes in those of acetic acid and ethanol were small. 
Table 3. Effect of resin on rate of carbon dioxide formation.

\begin{tabular}{ccc}
\multirow{2}{*}{$\begin{array}{c}\text { Amount of resin } \\
\left(\mathrm{mg} / 10^{9} \text { cells }\right)\end{array}$} & \multicolumn{2}{c}{$k_{\mathrm{Co}_{2}} / k^{a}$} \\
\hline 2.0 & before addition & after addition \\
4.0 & $0.15(0.03)^{b}$ & $0.32(0.01)^{b}$ \\
6.0 & $0.28(0.06)$ & $0.67(0.01)$ \\
\hline
\end{tabular}

a Ratio of rate constants: the rate constant of carbon dioxide formation to that of glucose uptake; corrected by the number of carbons.

$b$ The estimated standard error.

The summation of the ratios in Fig. 7 is smaller than one, the remaining part not reaching one probably being assigned to the ratio of carbon dioxide formation. This assumed ratio of carbon dioxide formation was enhanced as the amount of resin increased (dotted line in Fig. 7).

Direct measurement of the ratio of carbon dioxide formation by using ${ }^{14} \mathrm{C}$ labelled glucose was also executed (Table 3).

As shown in Table 3, the ratio of carbon dioxide formation was enhanced by the resin, and larger increases were observed with the amount of resin. The ratios in Table 3 are larger than those expected in Fig. 7. This will be due to the difference in experimental conditions: in the experiment using C-14 glucose, air was allowed to flow continuously at the rate of $10 \mathrm{ml} / \mathrm{min}$ to drive off carbon dioxide from the reaction mixture; this larger supply of air may accelerate the respiratory production of carbon dioxide.

The results in Table 3 and Fig. 7 are explained well in the following way: the transfer of electrons from the source located along the respiratory process to the resin caused the increase in the respiratory activity, and resulted in the enhancement of the formation of carbon dioxide.

\section{DISCUSSION}

Eschelichia coli can transfer electrons to resin as well as to the electrode, and its respiratory activity is enhanced by the resin when the oxygen supply is limited.

HATTORI et al. (4) pointed out that the cells adsorbed to the resin had a higher $\mathrm{pH}$ value in maximum oxidative activity than that of free cells. The electron transfer from cell to resin may be a reason for this phenomenon, because the resin surface will be negatively charged by the electron transfer and, consequently, cations will be attracted around the surface.

Allen et al. (7-9) proposed that the electron transfer from E. coli to an electrode was due primarily to the oxidation of hydrogen produced by the decomposition of formic acid by formic dehydrogenase. MATSUnAGa et al. (10) proposed, using $L$. fermenti, that from $\mathrm{NAD}(\mathrm{P}) \mathrm{H}$ and $\mathrm{FADH}_{2}$ electrons were released, and that these co-enzymes would be reduced again by the enzymes requiring NAD 
and FAD, such as glucose dehydrogenase, glucose-6-phosphate dehydrogenase, glutamate dehydrogenase, and amino acid oxidase.

These propositions suggest that an electron source other than that along the respiratory process may exist in other microorganisms and under different experimental conditions. When arsenite was added to the cell suspension metabolizing glucose, the current was not interrupted completely, as shown in Fig. 4b. From the other source, though small in quantity, electrons might be released.

Microorganisms may have various electron sources. If electron transfer from cells to liquid-solid interface is a common phenomenon, this will have an important bearing, as indicated in this work, in the understanding of the physiological properties of microorganisms in natural habitats abundant in various interfaces and those of fixed microorganisms in polymer matrices recently used industrially.

The author thanks Dr. T. Matsunaga for his helpful assistance in preparing the electrodes and Profs. C. Furusaka and T. Hattori for their useful suggestions during this work.

\section{REFERENCES}

1) T. Matsunaga, I. Karube, and S. Suzuki, Appl. Environ. Microbiol., 37, 117 (1979).

2) M. Dubois, K. A. Gilles, J. K. Hamilton, P. A. Rebers, and F. Smith, Anal. Chem., 28, 350 (1956).

3) N. R. Draper and H. Smith, Applied Regression Analysis (Japanese Translation), Morikita Shuppan, Tokyo, p. 20 (1973).

4 ) R. Hattori, T. Hattori, and C. Furusaka, J. Gen. Appl. Microbiol., 18, 271 (1972).

5) T. Hattori and C. Furusaka, J. Biochem., 48, 831 (1960).

6) R. Hattori, J. Gen. Appl. Microbiol., 22, 215 (1976).

7) M. J. Allen, R. J. Bowen, M. Nicholson, and B. M. Vasta, Electrochim. Acta, 8, 991 (1963).

8) M. J. Allen, Electrochim. Acta, 11, 7 (1966).

9) M. J. Allen, Electrochim. Acta, 12, 569 (1967).

10) T. Matsunaga, I. Karube, and S. Suzuki, Anal. Chim. Acta, 98, 25 (1978). 